\title{
Effect of Ag on the Microstructure, Mechanical and Bio-corrosion Properties of Fe-30Mn Alloy
}

\author{
Ruo-Yu Liu ${ }^{1} \cdot$ Ran-Gan He ${ }^{1} \cdot$ Yan-Xia Chen ${ }^{1}$. Sheng-Feng Guo ${ }^{1}$ \\ Received: 1 November 2018 / Revised: 10 April 2019 / Published online: 6 May 2019 \\ (c) The Chinese Society for Metals (CSM) and Springer-Verlag GmbH Germany, part of Springer Nature 2019
}

\begin{abstract}
In the current work, biodegradable $\mathrm{Fe}-30 \mathrm{Mn}-X \mathrm{Ag}(X=1,2,5,10 \mathrm{wt} \%)$ alloys were prepared by the rapid solidification with copper-mold-casting technology. Phase analysis demonstrates that $\mathrm{Fe}-30 \mathrm{Mn}-X \mathrm{Ag}$ alloys consist of austenite $\gamma$ phase with a fcc structure and martensite $\varepsilon$ phase with a hcp structure. The yield strength of the samples increases with increasing $\mathrm{Ag}$ contents. Compared with $\mathrm{Fe}-30 \mathrm{Mn}$ alloy, the degradation rates of $\mathrm{Fe}-30 \mathrm{Mn}-X \mathrm{Ag}$ in Hank's solution are significantly improved. Cytotoxicity evaluation reveals that the $\mathrm{Fe}-30 \mathrm{Mn}-1 \mathrm{Ag}$ and $\mathrm{Fe}-30 \mathrm{Mn}-2 \mathrm{Ag}$ alloys perform less toxicity on the Human Umbilical Vein Endothelial Cells (HUVEC), while Fe-30Mn-5Ag and Fe-30Mn-10Ag alloys perform no toxicity on it. The contact angles of deionized water on the Fe-30Mn-XAg alloy surface were ranged from $55^{\circ}$ to $69^{\circ}$, which is beneficial to the adhesion and growth of the cells. Besides, the addition of Ag leads to a much lower $M / H$ slope, particularly for the Fe-30Mn-5Ag alloy exhibiting a non-magnetic property as SS316L. Therefore, the present Fe-30Mn-XAg alloys would be potential candidates for degradable metals.
\end{abstract}

Keywords Biodegradable metals $\cdot$ Fe-based alloy $\cdot$ Corrosion behavior $\cdot$ Biocompatibility

\section{Introduction}

Biodegradable metals, which are considered as a new generation of biomedical materials and abandon the old design concept for metallic implants, with an expectation of degradable ability in vivo and repair function, have grown rapidly in the early twenty-first century [1-3]. For example, pure magnesium and magnesium alloys have great potential as biodegradable metallic materials. However, the results of the in vivo test are not satisfactory for their fast degradation rate with a large amount of hydrogen releases $[4,5]$. In other case, $\mathrm{Fe}$ is also regarded as an interesting and attractive alternative candidate, since it is essential for human body and always works in many biochemical reactions $[6$, 7]. More importantly, pure $\mathrm{Fe}$ has been confirmed to possess limited toxicity by either in vitro $[8,9]$ or in vivo $[10$, 11] investigations. Unfortunately, pure Fe has an extremely

Available online at http://link.springer.com/journal/40195

Sheng-Feng Guo

sfguo@swu.edu.cn

1 School of Materials and Energy, Southwest University, Chongqing 400715, China slow degradation rate in body fluids [10, 12-14], leading it to maintain its integrity after 12-month implantation [12].

Lately, a batch of $\mathrm{Fe}-\mathrm{Mn}$ alloys was recommended due to their faster degradation, better mechanical compatibility and magnetic resonance imaging (MRI) compatibility compared with pure iron $[15,16]$. To further accelerate the degradation rate, microalloying with C [17], Si [18], Pd [14] or Ag [19] in biodegradable $\mathrm{Fe}-\mathrm{Mn}$ metals is considered to be a good method. The reasons for this are: First, the matrix has a lower standard electrode potential. Second, the precipitates in the matrix could induce microgalvanic corrosion and hence accelerate the degradation rate. In addition, as biodegradable implants, good biocompatibility is another crucial property for clinical application. In our previous work, we found that $\mathrm{Ag}$-bearing $\mathrm{Fe}-30 \mathrm{Mn}$ alloys exhibit better mechanical properties and increased compatibility of MRI [19] with an accelerated degradation rate. However, the biocompatibility of Ag-bearing $\mathrm{Fe}-30 \mathrm{Mn}$ alloys has not been explored. In this work, biodegradable Fe-30Mn alloy with different contents of $\mathrm{Ag}$ was developed. The degradation characteristics, mechanical properties, magnetic susceptibility and biocompatibility of these alloys were systematically investigated. 


\section{Experimental}

The master alloys of Fe-30Mn-XAg $(X=1,2,5,10 \mathrm{wt} \%)$ were fabricated by arc-melting in an Ar atmosphere followed by rapid solidification with water-cooling copper mold casting. The alloy rods with $3 \mathrm{~mm}$ in diameter and $50 \mathrm{~mm}$ in length were fabricated using the industrial purity of $\mathrm{Fe}(99.5 \mathrm{wt} \%)$, pure $\mathrm{Mn}(99.9 \mathrm{wt} \%)$ and pure $\mathrm{Ag}$ (99.99 wt\%). A Rigaku D/MAX-2500/PC X-ray diffraction (XRD) with a $\mathrm{Cu}$ radiation and a JSM-6610A scanning electron microscope (SEM) with an X-ray energy-dispersive spectrometer (EDS) were performed on the microstructure and phase identification. The microstructure was also observed by transmission electron microscopy (TEM, FEI Tecnai F20). The thin foil specimen was prepared by twin-jet electropolishing in a solution of $10 \%$ $\mathrm{HClO}_{4}$ and $90 \% \mathrm{C}_{2} \mathrm{H}_{6} \mathrm{O}$ at a temperature of $-30{ }^{\circ} \mathrm{C}$ and finally cleaned by low-angle ion milling for TEM observation. For mechanical tests, the compressive samples were cut with an aspect ratio of 2:1 and a mechanical testing machine (Reger, RGM-4100) was used with a strain rate of $5 \times 10^{-4} \mathrm{~s}^{-1}$. The magnetic performance was recorded by the vibrating sample magnetometer (VSM, Quantum Design, VersaLab).

Before the electrochemical tests, each sample was embedded by epoxy resin with an end surface area exposed, which was ground with silicon carbide papers up to 3000 grit, and then cleaned in absolute ethyl alcohol ultrasonically, followed by washing in distilled water and air-drying. In this study, electrochemical tests were carried out in an electrochemical workstation (CHI660E) with a three-electrode cell by putting the specimen, a platinum electrode and a saturated calomel electrode (SCE) into Hank's solution at $37 \pm 0.5{ }^{\circ} \mathrm{C}$. Prior to the open-circuit potential (OCP) measurement, all the samples were soaked for $20 \mathrm{~min}$ in order that the stability of the following experiment can be ensured. The potentiodynamic polarization behavior was measured at a scanning rate of $0.33 \mathrm{mV} / \mathrm{s}$ when the OCP reached a steady state. The micrographs and chemical composition of the corrosion products were characterized by SEM with EDS. According to ASTM-G31-72 standard, the static immersion tests were carried out at $37{ }^{\circ} \mathrm{C}$ in water bath for $1,2,4,8$ and 12 weeks, respectively. After immersed for 2 weeks and 4 weeks, the element concentrations released into the solutions were detected by ICP-OES (PE, Optima 8000).

The cytotoxicity tests were performed on HUVEC. Dulbecco's modified Eagle's medium (DMEM) was used for the preparation of the extraction medium. The ratio of sample surface area to extraction medium was $3 \mathrm{~cm}^{2} /$ $\mathrm{mL}$. Cells were incubated at $5 \times 10^{3}$ cells $/ 100 \mu \mathrm{L}$ medium for $72 \mathrm{~h}$ in $96-$ well cell culture plates. Subsequently, the concentration of the extraction medium was diluted to $10 \%$. Then, $100 \mu \mathrm{L}$ of extraction medium replaced the medium and incubated for 1, 2 and 4 days, followed by adding $10 \mu \mathrm{L}$ MTT to each well and incubating for $4 \mathrm{~h}$ at $37^{\circ} \mathrm{C}$. Next, $100 \mu \mathrm{L}$ DMSO (dimethyl sulfoxide) was put in each well for $15 \mathrm{~min}$ in the incubator. The absorbance of the specimens was carried out by a microplate reader (Spark, Tecan) at $570 \mathrm{~nm}$. In addition, the liquid drop method was used for the static contact angle of deionized water on the alloy surface with a deionized water droplet of $10 \mu \mathrm{L}$ by using a goniometer (Data Physics OCA25).

\section{Results and Discussion}

Figure 1 displays the XRD patterns from four different as-cast alloys. According to the standard PDF card (Reference code: 06-0696) and the typical Fe-Mn binary phase diagram [20], silver cannot form the solid solution in iron. The composition of the phase and microstructure of the $\mathrm{Fe}-30 \mathrm{Mn}-X \mathrm{Ag}$ alloys are confirmed, which consist of austenite $\gamma$ phase with a fcc structure and martensite $\varepsilon$ phase with a hcp structure. The presence of the martensite $\varepsilon$ phase is probably originated from the process, which form a supersaturated solid solution of metastable $\alpha$-ferrite with silver element during the rapid solidification of $\mathrm{Fe}-30 \mathrm{Mn}$ alloy. Moreover, it can be seen that the content of the martensitic $\varepsilon$ phase decreases with the increase in silver content, implying that extremely low solid solubility of silver in austenite $\gamma$ phase is even under rapid cooling.

Figure 2 exhibits the SEM and TEM images of the $\mathrm{Fe}-30 \mathrm{Mn}-X \mathrm{Ag}$ alloys with different silver contents. It can be obviously found that some bright particles appear at the grain boundaries. With increasing silver, the particle

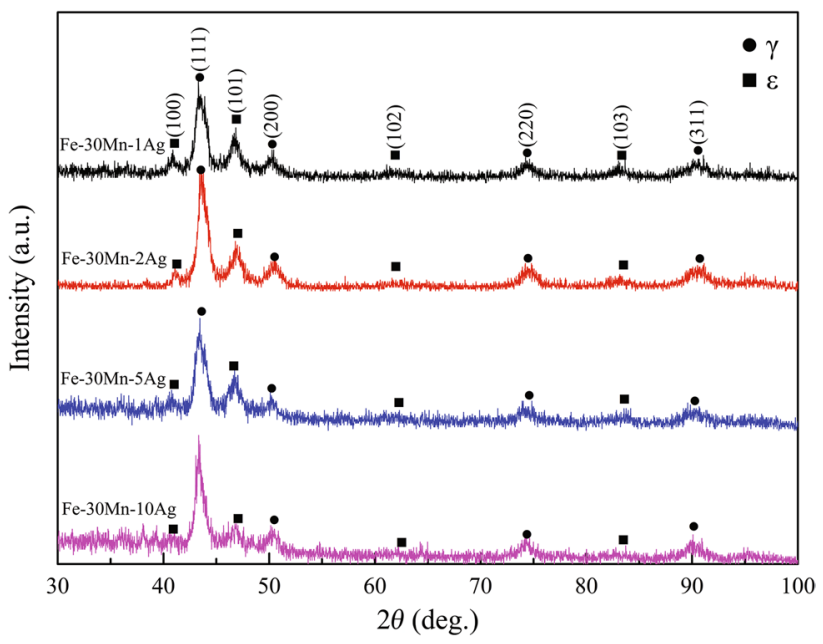

Fig. 1 XRD patterns of the as-cast Fe-30Mn- $X$ Ag alloys $(X=1,2,5$ and 10) 

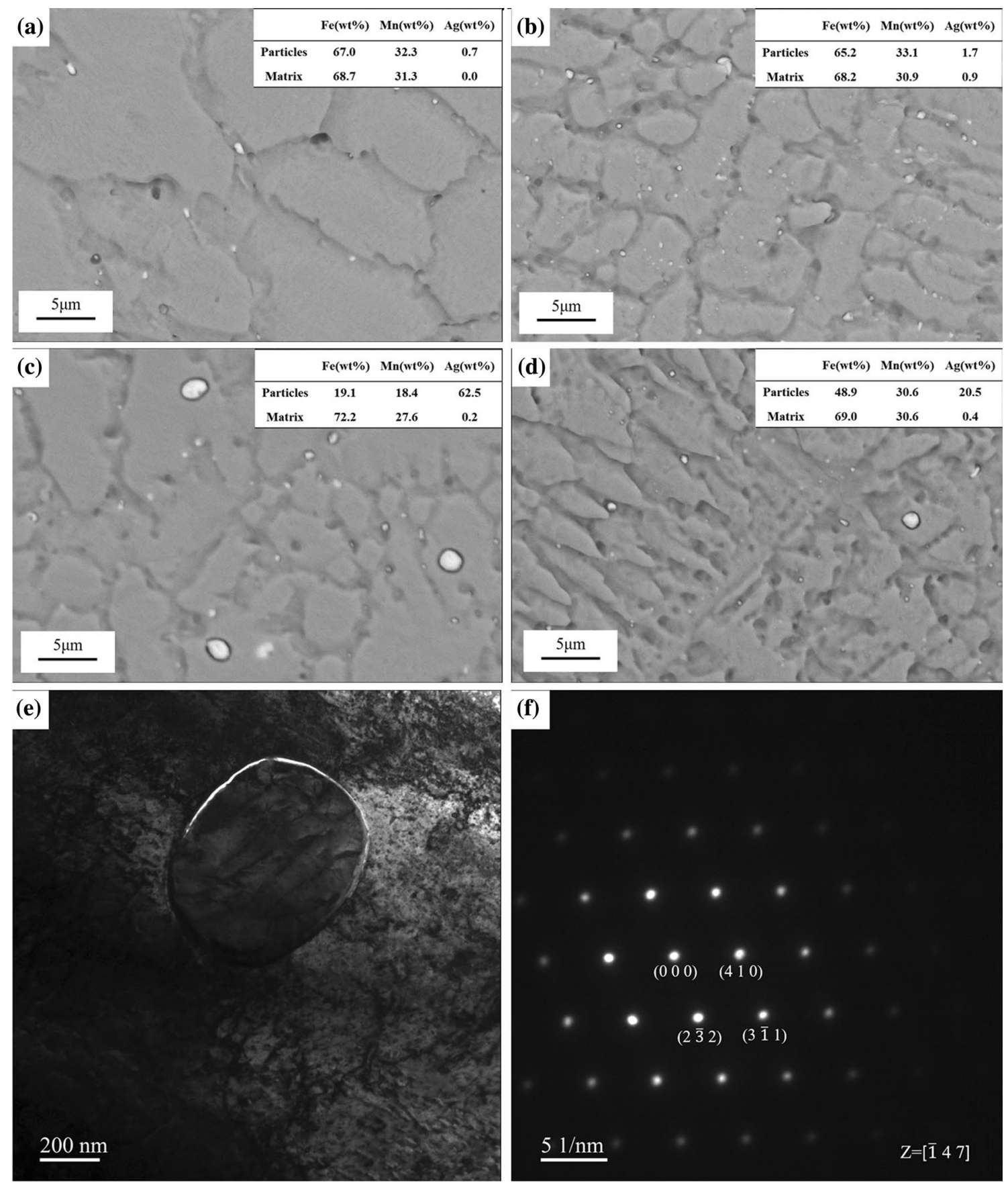

Fig. 2 SEM backscattered electron images of Fe-30Mn-1 Ag a; Fe-30Mn-2Ag b; Fe-30Mn-5Ag c; Fe-30Mn-10Ag alloys d; the TEM bright field image $\mathbf{e}$, the SAED pattern $\mathbf{f}$ of the bright particles for $\mathrm{Fe}-30 \mathrm{Mn}-5 \mathrm{Ag}$ alloy

contents were also increased. To identify the composition of the bright particles, the point analysis of EDS was performed. The weight percentage of the silver in the precipitated particles was far more than that in the alloy matrix, suggesting that these bright particles are silver-enriched particles. In addition, the grain size of the as-cast alloy decreases clearly with the increase in Ag content owing to the formation of many silver-enriched particles acting as heterogeneous nucleus. In order to further identify the structure and phase composition of the bright particles, the TEM bright field image and the corresponding selected area electron diffraction (SAED) pattern of the bright particles for $\mathrm{Fe}-30 \mathrm{Mn}-5 \mathrm{Ag}$ alloy are shown in Fig. 2e, f, respectively. It was demonstrated that the silver-enriched particles were $\mathrm{Ag}_{3} \mathrm{Fe}_{2}$ phase with a BCC structure. The SAED pattern was indexed as the [1147] zone of $\mathrm{Ag}_{3} \mathrm{Fe}_{2}$ phase. 


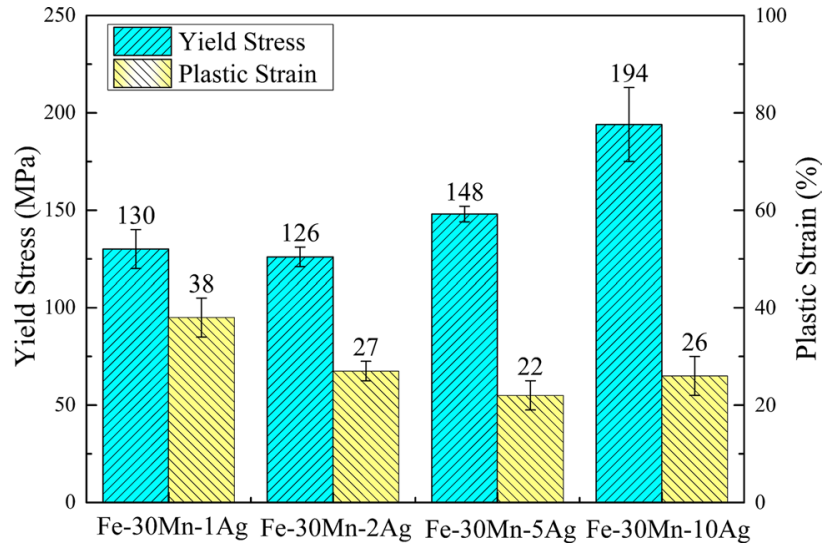

Fig. 3 Compressive yield strength and plastic strain of different alloys

Figure 3 shows the plastic strain and the yield strength obtained by the compression test. The yield strength of $\mathrm{Fe}-30 \mathrm{Mn}$ alloy is only approximately $94 \mathrm{MPa}$ as a result of the $\gamma$ phase formation [19]. The solid solubility of silver in iron and manganese matrix is very low. Therefore, Ag can only be precipitated at the grain boundaries with $\mathrm{Ag}_{3} \mathrm{Fe}_{2}$ phases. These particles inhibit grain growth and make the grain be refined, improving the mechanical properties of these alloys. A higher compressive yield strength of $130 \mathrm{MPa}$ for $\mathrm{Fe}-30 \mathrm{Mn}-1 \mathrm{Ag}$ alloy is found owing to the precipitation of $\mathrm{Ag}_{3} \mathrm{Fe}_{2}$ phases on the grain boundaries. The increase in the compressive yield strength of the sample increases with silver which is likely to put down to the coupled effects of the discrete particles and the grain refinement. Furthermore, each $\mathrm{Fe}-30 \mathrm{Mn}-X \mathrm{Ag}$ alloy in this study exhibits a pretty good room-temperature deformation ability, revealing that all of the $\mathrm{Fe}-30 \mathrm{Mn}-X \mathrm{Ag}$ alloys are readily processable implants. The mechanical properties of the current as-cast Ag-bearing Fe-based biodegradable alloys approach that of general 316L stainless steel, and therefore, it can be considered a gold standard material used for stents [21].

Figure $4 \mathrm{a}$ shows the change in OCP of four diverse $\mathrm{Fe}-30 \mathrm{Mn}-X \mathrm{Ag}$ alloys during the immersion time up to $3600 \mathrm{~s}$. During testing, the value of OCP remained relatively stable, implying the fine thermodynamic stability of spontaneous passive film. The four potentiodynamic polarization curves of the specimens measured in simulated body fluid (Hank's) are shown in Fig. 4b. Different with pure iron where pitting corrosion behavior always occurs [22], the Ag-bearing Fe-based biodegradable metals exhibit a clear passivation region. Some corrosion kinetics parameters are given in Table $1 . E_{\text {corr }}$ and $i_{\text {corr }}$ are the corrosion potential and the corrosion current density, respectively. Both of the two parameters are calculated by Tafel extrapolation method. On the basis of the results of electrochemistry, the $i_{\text {corr }}$ basically follows the next sequence: $\mathrm{Fe}-$
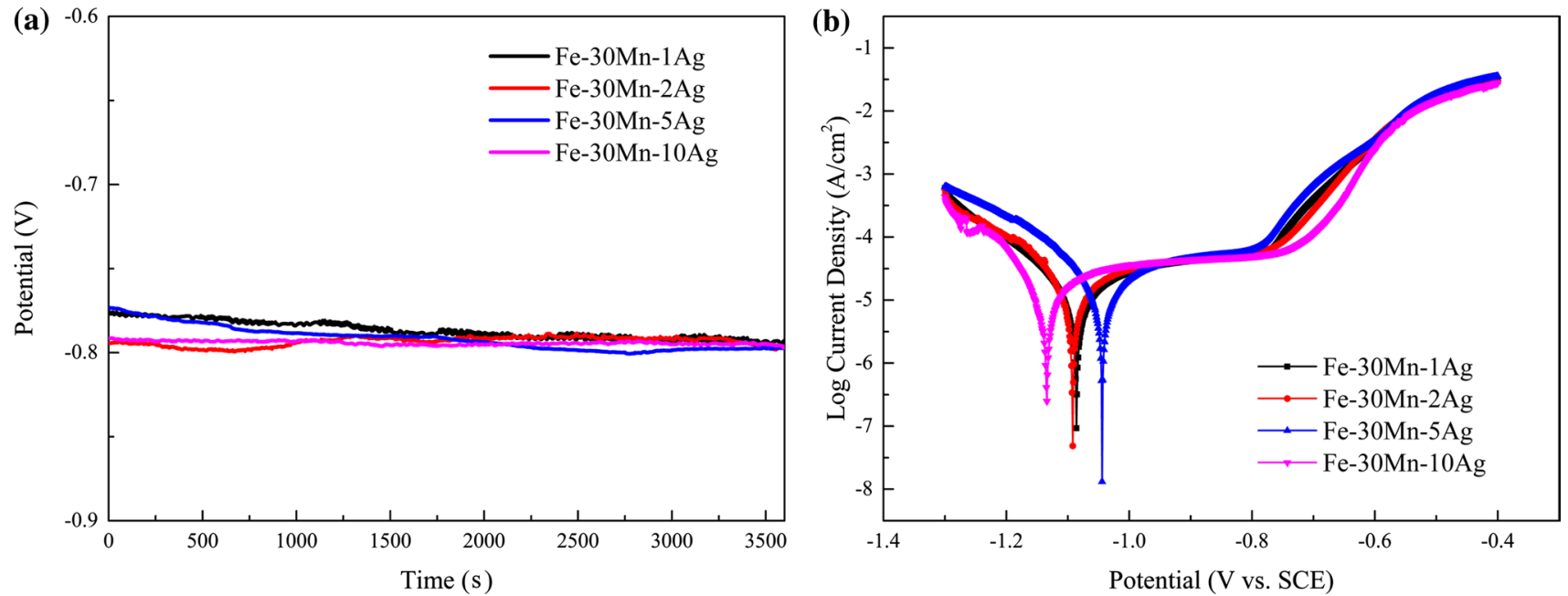

Fig. 4 OCP $\mathbf{a}$ and potentiodynamic polarization curves $\mathbf{b}$ of different samples in Hank's solution

Table 1 Electrochemical corrosion parameters and magnetic susceptibility of $\mathrm{Fe}-$ $\mathrm{Mn}-X \mathrm{Ag}$ alloys

\begin{tabular}{lllclll}
\hline Samples & OCP $(\mathrm{V})$ & $E_{\text {corr }}(\mathrm{V})$ & $i_{\text {corr }}\left(\mu \mathrm{A} / \mathrm{cm}^{2}\right)$ & $R_{\mathrm{p}}\left(\Omega / \mathrm{cm}^{2}\right)$ & $P(\mathrm{~mm} / \mathrm{a})$ & $\chi\left(\mathrm{m}^{3} / \mathrm{kg}\right)$ \\
\hline Fe-30Mn-1Ag & -0.79 & -1.09 & 7.33 & $3.33 \times 10^{5}$ & 0.088 & $2.16 \times 10^{-6}$ \\
Fe-30Mn-2Ag & -0.79 & -1.06 & 9.17 & $2.17 \times 10^{5}$ & 0.113 & $2.00 \times 10^{-6}$ \\
Fe-30Mn-5Ag & -0.80 & -1.04 & 10.52 & $1.73 \times 10^{5}$ & 0.143 & $6.06 \times 10^{-7}$ \\
Fe-30Mn-10Ag & -0.80 & -1.15 & 7.40 & $2.42 \times 10^{5}$ & 0.128 & $1.03 \times 10^{-6}$ \\
\hline
\end{tabular}


$30 \mathrm{Mn}-5 \mathrm{Ag}>\mathrm{Fe}-30 \mathrm{Mn}-2 \mathrm{Ag}>\mathrm{Fe}-30 \mathrm{Mn}-10 \mathrm{Ag}>\mathrm{Fe}-30 \mathrm{Mn}-$ $1 \mathrm{Ag}$. The $\mathrm{Fe}-30 \mathrm{Mn}-5 \mathrm{Ag}$ alloy exhibits a highest value of $i_{\text {corr }}$ among the Ag-bearing Fe-based alloys, suggesting that there is a significant increase in the degradation rate. It should be mentioned that the $i_{\text {corr }}$ of Fe-30Mn-10Ag started to decrease, which probably relates to the alloy with much finer dendritic microstructure that will be easier to prevent the expansion of corrosion [23-25]. Moreover, the linear polarization resistances $\left(R_{\mathrm{p}}\right)$ can be calculated from the Stern-Geary equation as follows:

$i_{\text {corr }}=\frac{\beta_{\mathrm{a}} \times \beta_{\mathrm{c}}}{2.3 R_{\mathrm{p}} \times\left(\beta_{\mathrm{a}}+\beta_{\mathrm{c}}\right)}$,

where anodic Tafel slope $\left(\beta_{\mathrm{a}}\right)$ and the cathodic Tafel slope $\left(\beta_{\mathrm{c}}\right)$ can be obtained from polarization curves. The Fe-30Mn-5Ag alloy shows the lowest $R_{\mathrm{p}}$, where the resulting degradation films expose the metal surface in the corrosive medium and increase metal dissolution. The corrosion rate $(P, \mathrm{~mm} / \mathrm{a})$ can be identified by Faraday's law [12] as shown in Eq. (2):

$P=0.00327 \times \frac{\mathrm{EW} \times i_{\text {corr }}}{d}$, where $\mathrm{EW}, i_{\text {corr }}\left(\mu \mathrm{A} / \mathrm{cm}^{2}\right)$ and $d\left(\mathrm{~g} / \mathrm{cm}^{3}\right)$ are the equivalent weight, the corrosion current density and the materials density, respectively. The corrosion rates of Ag-bearing Febased alloys are in good agreement with the results of $R_{\mathrm{p}}$ and $i_{\text {corr }}$, indicating that the $\mathrm{Fe}-30 \mathrm{Mn}-5 \mathrm{Ag}$ alloy shows a fastest degradation rate.

To further understand the degradation behavior, the corrosion morphologies of the specimens were recorded by SEM when the pitting corrosion had just appeared. There were no corrosion products on the corroded surface of Fe-30Mn-1 Ag alloy (see Fig. 5a). The depth of corrosion dendrites became much deeper accompanied with the formation of corrosion layer, implying that the degradation rate was accelerated with the increase in $\mathrm{Ag}$ contents. It can be found that some corrosion products were formed and parts of the surface of $\mathrm{Fe}-30 \mathrm{Mn}-2 \mathrm{Ag}$ alloy were covered (see Fig. 5b). For the Fe-30Mn-5Ag alloy, the corrosion film was near-fully covered on the alloy surface (see Fig. 5c). However, the surface of Fe-30Mn-10Ag alloy was smooth. Only a little corrosion product was found around the pits (see Fig. 5d). These results are also consistent with the corrosion rate calculated by electrochemical method.

Figure 6a shows the mass loss variation of different specimens with the evolution of static immersion time. After 1 -week immersion, the sample has little loss of mass. From
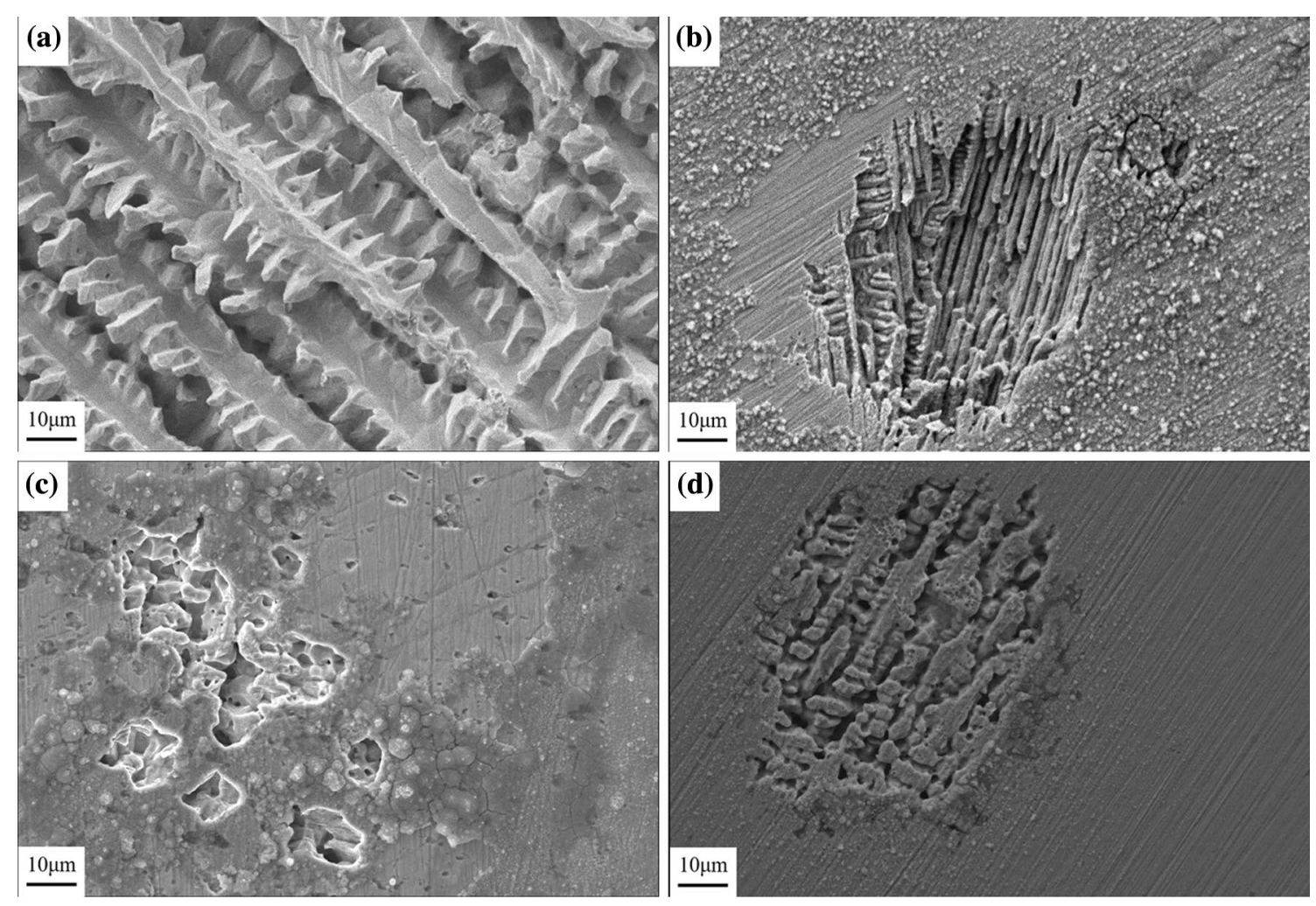

Fig. 5 Corrosion morphologies of Fe-30Mn-1 Ag a, Fe-30Mn-2Ag b, Fe-30Mn-5Ag c, Fe-30Mn-10Ag d alloys after potentiodynamic polarization test up to pitting 

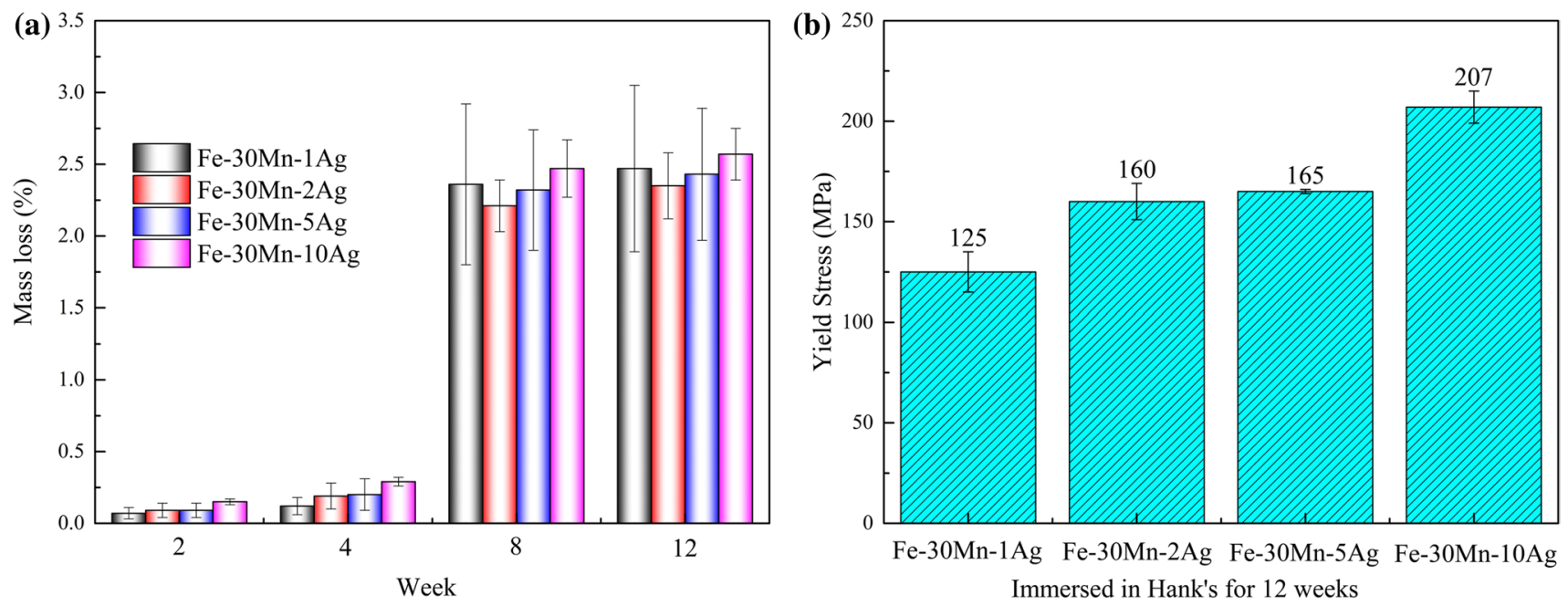

Fig. 6 Percentage of mass loss $\mathbf{a}$ and compressive yield strength $\mathbf{b}$ of the samples after 12-week immersion

2- to 4-week immersion, the mass loss of the samples began to increase slightly, but still no more than $0.3 \%$. When the sample was immersed after 8 weeks, the percentage of their mass loss reached $2 \%$. Pitting corrosion become more evident when the corrosion products covered and the samples were longer exposed in the corrosion medium, where aggressive ions such as chlorides were present [26]. After 12-week immersion, the percentage of mass loss reached $2.6 \%$. The progress of weight loss rate did not change significantly after 8 weeks, which may be attributed to the passivating film formed on the alloy surface. There is no precipitation in the solution, and the corrosion products adhered to the surface of the samples. Furthermore, the structural integrity cannot be failure before the diseased tissues were recovered. If not, it can have a negative effect on healing and can bring about deterioration [1]. It should be noted that mechanical integrity for Fe-30Mn-XAg alloys was still maintained after 3-month immersion, as indicated by the almost same of compressive yield strength as the alloys without immersion (see Figs. 3 and 6b).

Figure 7 exhibits the corroded surfaces of the four alloys, which are immersed in simulated body fluid (Hank's) after 12 weeks. The alloy surfaces show seriously to be corroded, which were fully covered with corrosion products. Enlarged pictures can clearly show the morphologies of corrosion products. Figure $7 \mathrm{a}, \mathrm{b}$ and $\mathrm{d}$ shows that the corrosion products are coral-like particles. However, the corrosion product particles in Fig. 7c are much larger than those of other samples, which may result from the fastest degradation of $\mathrm{Fe}-30 \mathrm{Mn}-5 \mathrm{Ag}$ alloy. EDS element composition of the corrosion products revealed that the main component was $\mathrm{Fe}(\mathrm{OH})_{3}$.

Microgalvanic corrosion was introduced between the alloy matrix and the precipitates at the grain boundaries.
The $\mathrm{Ag}_{3} \mathrm{Fe}_{2}$ phases have a much higher corrosion potential compared with the Fe-Mn alloy matrix. Consequently, the Fe-Mn alloy matrix serving as the anode would be oxidized, as shown in Eqs. (3) and (4). The electrons created by the dissolving $\mathrm{Fe}-\mathrm{Mn}$ alloy matrix would be transferred to the $\mathrm{Ag}_{3} \mathrm{Fe}_{2}$ phases as the cathode. After that, the dissolved oxygen would consume these electrons, as shown in Eq. (5). The schematic diagram of the anode and cathode reactions is illustrated in Fig. 8a.

$\mathrm{Fe} \rightarrow \mathrm{Fe}^{2+}+2 e^{-}$(anode reaction),

$\mathrm{Mn} \rightarrow \mathrm{Mn}^{2+}+2 e^{-}$(anode reaction),

$2 \mathrm{H}_{2} \mathrm{O}+\mathrm{O}_{2}+4 e^{-} \rightarrow 4 \mathrm{OH}^{-}$(cathode reaction).

The formation of iron hydroxide was caused by the increase in the $\mathrm{pH}$ value of the solution near the $\mathrm{Ag}_{3} \mathrm{Fe}_{2}$ phases as shown in Eq. (6). Since the ferrous hydroxide was thermodynamic instability, it would be further oxidized to ferric hydroxide [see Eq. (7)]. The schematic diagram of corrosion processes is given in Fig. $8 \mathrm{~b}$.

$\mathrm{Fe}^{2+}+2 \mathrm{OH}^{-} \rightarrow \mathrm{Fe}(\mathrm{OH})_{2}$,

$4 \mathrm{Fe}(\mathrm{OH})_{2}+\mathrm{O}_{2}+2 \mathrm{H}_{2} \mathrm{O} \rightarrow 4 \mathrm{Fe}(\mathrm{OH})_{3}$.

The ions produced could be released when the metals are in the corrosive environment. Nevertheless, excessive metals in human body are toxic. After static immersion, the samples would release metal ions. The concentrations of metal ions released are shown in Fig. 9. When the Fe-30Mn-1Ag alloy was immersed for 4 weeks and the Fe-30Mn-10Ag alloy was immersed for 2 weeks, there were no Fe ions detected. It is because the formation of solid corrosion products can retain $\mathrm{Fe}$ ions. In addition, there are no $\mathrm{Ag}$ ions detected. 

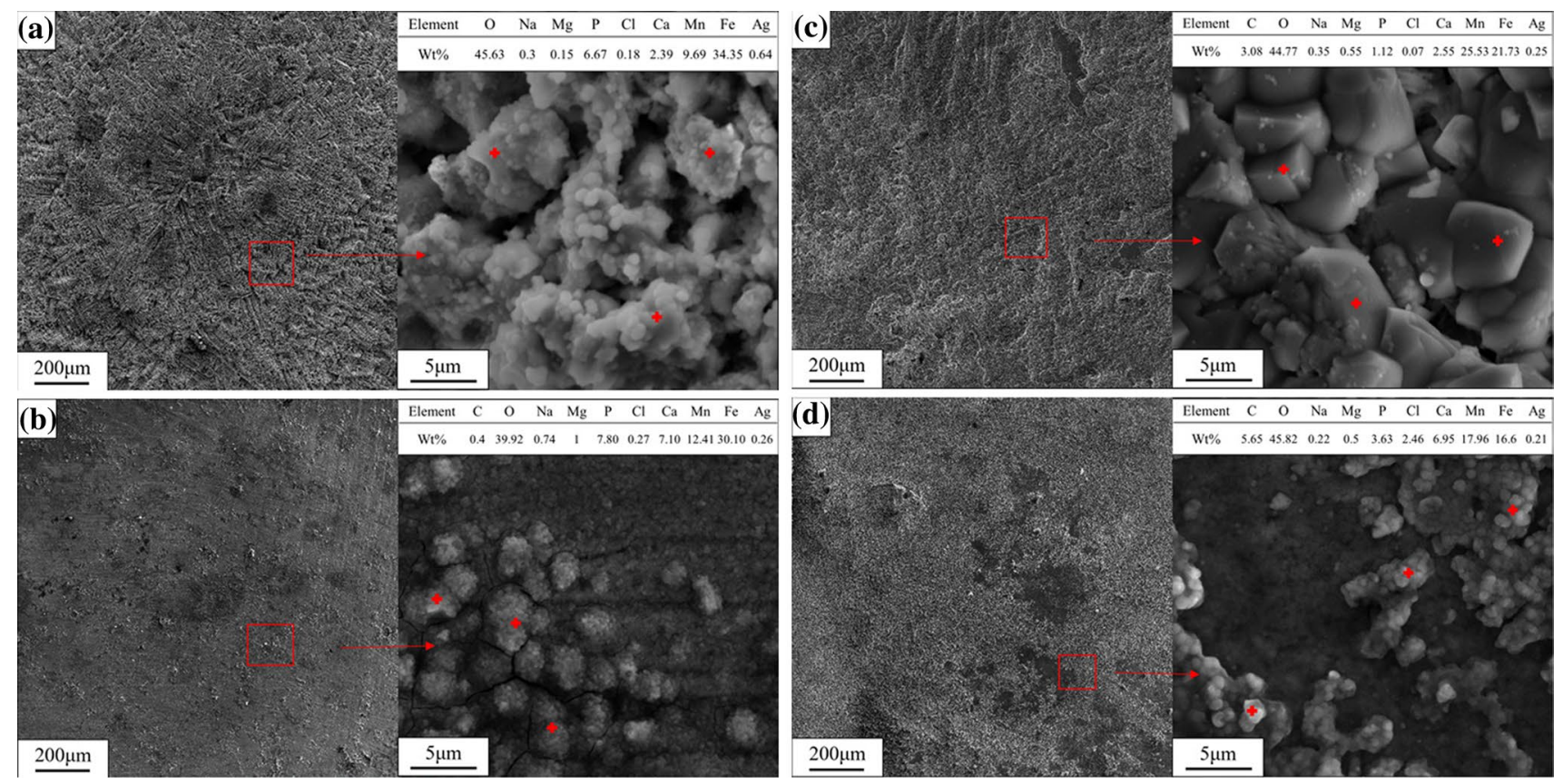

Fig. 7 Corrosion morphologies of Fe-30Mn-1 Ag a, Fe-30Mn-2Ag b, Fe-30Mn-5Ag c, Fe-30Mn-10Ag d alloys after 12-week immersion and the EDS of corrosion products

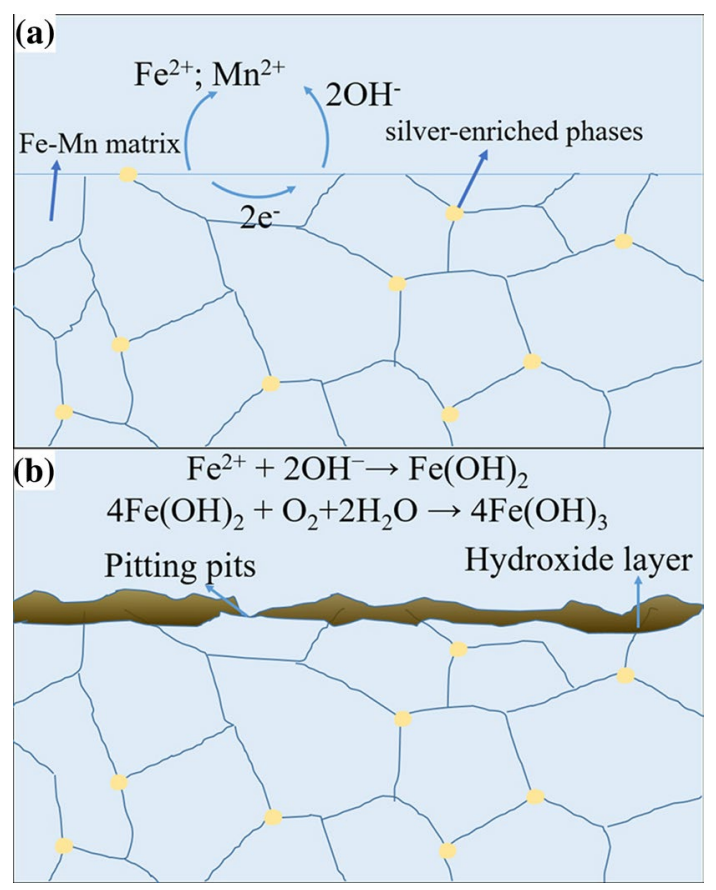

Fig. 8 Schematic diagram of corrosion mechanism for Fe-30Mn$X \mathrm{Ag}$ alloys in Hank's solution

This is mainly attributed to that there is basically no silver in the matrix of the sample prepared by rapidly solidification. The total ion concentration of $\mathrm{Fe}-30 \mathrm{Mn}-5 \mathrm{Ag}$ alloy was higher than that of the other three samples, demonstrating

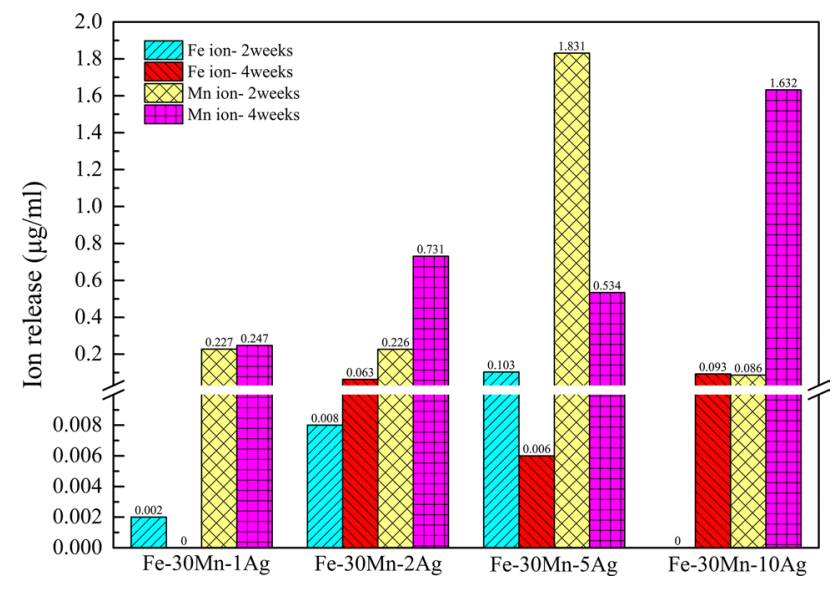

Fig. 9 Ion concentrations of Fe30Mn- $X \mathrm{Ag}$ after immersion in Hank's solution for 2 and 4 weeks, respectively

that the $\mathrm{Fe}-30 \mathrm{Mn}-5 \mathrm{Ag}$ alloy possesses the fastest degradation rate.

The released metallic ions [15] and degradation particles [27] could cause the cytotoxicity of biodegradable materials. It was well known that iron was an essential element for human body. When the concentration of iron reached a high level, it may be toxic, and its concentration in the serum was $3.5-5 \mu \mathrm{g} / \mathrm{mL}$ [28]. In addition, manganese was also the essential element for human, and it had potential toxicity, i.e., a level of $3-5.6 \mu \mathrm{g} / \mathrm{dL}$ could cause neurologic symptoms [29]. It was in vitro cytotoxicity that was defined 
as the proportion of metabolism. And this test was carried out by extracts with a dilution of $10 \%$. Figure 10 illustrates the cell viabilities of Human Umbilical Vein Endothelial Cells (HUVEC). It exhibited by the proportion of cytoactive in which the survival of cells is compared with that of the control group. When the cells were incubated in different extraction mediums for different days, there are some differences. As time goes on, the cell activity of all the alloys was almost decreased. However, the cell viability was slightly increased with the increase in $\mathrm{Ag}$ content, even the cytoactive of $\mathrm{Fe}-30 \mathrm{Mn}-1 \mathrm{Ag}$ and $\mathrm{Fe}-30 \mathrm{Mn}-2 \mathrm{Ag}$ was below $70 \%$ after 4 days. According to ISO 10993-5:1999 standard, the cell viability with higher than $70 \%$ could be considered a medical device without a risk of toxicity. Iron ion concentrations in the four sample extracts were all lower than $3.5 \mu \mathrm{g} /$ $\mathrm{mL}$, but the manganese ion concentrations were higher than $5.6 \mu \mathrm{g} / \mathrm{dL}$ (see Fig. 9), which may cause the cell viability lower than $70 \%$. The $\mathrm{Ag}_{3} \mathrm{Fe}_{2}$ particles would be released into the body finally, but their concentration was very low. Therefore, the concentration of silver ions would be relatively low. In addition, the body fluid was a flowing system, so ions would flow in the system and be diluted [30, 31], which would not cause toxicity. In general, there was no significant toxicity for the Ag-bearing Fe-based alloys except $\mathrm{Fe}-30 \mathrm{Mn}-1 \mathrm{Ag}$ alloy.

There was a strong correlation between the cell adhesion and surface property of the materials. For example, implant wettability had an effect on the protein adsorption and further on the cell adhesion [32]. The hydrophilic surfaces would exhibit a better cell-attachment ability and spreading than the hydrophobic surface, and the highest level of cell attachment could be promoted by moderate hydrophilic surface [33]. Figure 11 presents the contact angle of $\mathrm{Fe}-30 \mathrm{Mn}-\mathrm{XAg}$ alloys. It can be seen that the contact angles

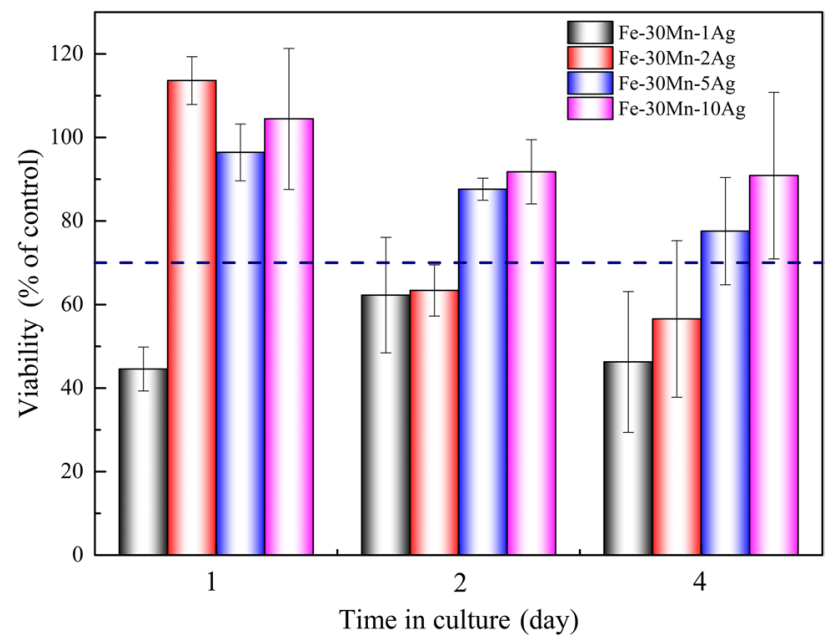

Fig. 10 Cell viability of HUVEC after 1, 2 and 4 days incubation in $10 \%$ extracts

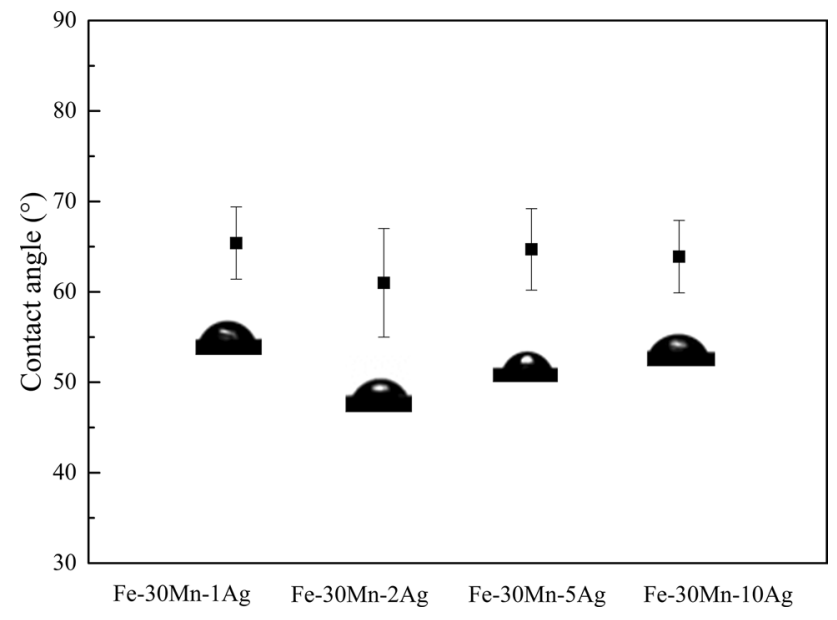

Fig. 11 Static contact angle of deionized water on $\mathrm{Fe}-30 \mathrm{Mn}-X \mathrm{Ag}$ alloy surface

of the $\mathrm{Fe}-30 \mathrm{Mn}-X \mathrm{Ag}$ alloys ranged from $55^{\circ}$ to $69^{\circ}$, which were within the range of $45^{\circ}-76^{\circ}$ reported to support attachment of mammalian cells [34]. Therefore, the surface of present $\mathrm{Fe}-30 \mathrm{Mn}-X \mathrm{Ag}$ alloys was suitable for cell adhesion.

Figure 12 displays the magnetization curves of $\mathrm{Fe}-30 \mathrm{Mn}-X \mathrm{Ag}$ alloys. It can be seen that all $\mathrm{Fe}-30 \mathrm{Mn}-X \mathrm{Ag}$ alloys exhibit paramagnetism. The magnetic susceptibility $M / H$, the ratio of magnetization $M$ (magnetic moment per unit volume) to the applied magnetizing field intensity $H$, of Fe-30Mn-XAg alloys was lower than that of Fe [19]. Adding manganese into Fe-based alloy could form austenitic phase, resulting in an enhanced compatibility of magnetic resonance imaging. In Table 1, it can be seen that the magnetic susceptibility of $\mathrm{Fe}-30 \mathrm{Mn}-X \mathrm{Ag}$ alloys was similar to that of the SS316L stainless steel [16]. When the

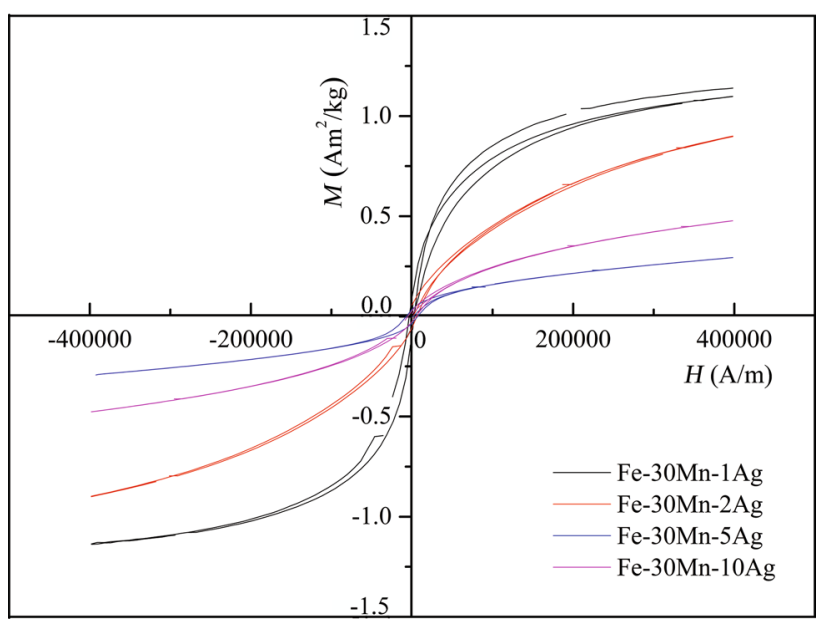

Fig. 12 Magnetic hysteresis loops of the as-cast $\mathrm{Fe}-30 \mathrm{Mn}-\mathrm{XAg}$ alloys 
silver content was added to $5 \%$, the magnetic susceptibility was decreased to $6.06 \times 10^{-7} \mathrm{~m}^{3} / \mathrm{kg}$, which was attributed to the diamagnetic effect of $\mathrm{Ag}\left(\chi_{\mathrm{Ag}}=-17.5 \times 10^{-6}\right)$ [35]. Compared with $\mathrm{Fe}-30 \mathrm{Mn}-5 \mathrm{Ag}$ alloy, the silver content of the precipitated particles of $\mathrm{Fe}-30 \mathrm{Mn}-10 \mathrm{Ag}$ alloy was decreased as shown in the EDS (see Fig. 2d), which was probably attributed to the formation of a new phase. Therefore, the magnetic susceptibility of $\mathrm{Fe}-30 \mathrm{Mn}-10 \mathrm{Ag}$ was higher than that of $\mathrm{Fe}-30 \mathrm{Mn}-5 \mathrm{Ag}$. In general, the compatibility of nuclear magnetic resonance was closely related to low magnetic susceptibility.

\section{Conclusion}

In the present work, degradable $\mathrm{Fe}-30 \mathrm{Mn}-X \mathrm{Ag}$ alloys were fabricated by rapid solidification with copper mold suction casting. The mechanical properties and degradation performance could be increased with the Ag addition. The novel $\mathrm{Fe}-30 \mathrm{Mn}-5 \mathrm{Ag}$ alloy exhibited a higher degradation rate than the other three alloys. With increasing addition of $\mathrm{Ag}$, there were no evident cytotoxicity and no obvious difference in the contact angle, which was always in a good range. In addition, the $\mathrm{Fe}-30 \mathrm{Mn}-X \mathrm{Ag}$ alloys possessed a well magnetic compatibility, especially for $\mathrm{Fe}-30 \mathrm{Mn}-5 \mathrm{Ag}$ alloy. Therefore, the developed $\mathrm{Fe}-30 \mathrm{Mn}-5 \mathrm{Ag}$ alloy can be a good candidate for degradable metal.

Acknowledgements This work was financially supported by the National Natural Science Foundation of China (No. 51671162) and the Fundamental Research Funds for the Central Universities (No. XDJK2017B054). This work was also supported in part by Chongqing Research Program of Basic Research and Frontier Technology (No. cstc2015jcyjBX0107) and the Venture and Innovation Support Program for Chongqing Overseas Returnees (No. cx2017086).

\section{References}

[1] Y.F. Zheng, X.N. Gu, F. Witte, Mater. Sci. Eng. R 77, 1 (2014)

[2] Y.J. Wang, J. Mater. Sci. Technol. 32, 799 (2016)

[3] C. Wang, H.T. Yang, Y.F. Zheng, J. Mater. Sci. Technol. 32, 909 (2016)

[4] H. Hermawan, H. Alamdari, D. Mantovani, D. Dubé, Powder Metall. 51, 38 (2008)

[5] F. Witte, J. Fischer, J. Nellesen, H.A. Crostack, V. Kaese, A. Pisch, F. Beckmann, H. Windhagen, Biomaterials 27, 1013 (2006)

[6] N. Abbaspour, R. Hurrell, R. Kelishadi, J. Res. Med. Sci. 19, 164 (2014)

[7] T. Ganz, Physiol. Rev. 93, 1721 (2013)
[8] J. Čapek, J. Kubásek, D. Vojtěch, E. Jablonska, J. Lipov, T. Ruml, Mater. Sci. Eng. C 58, 900 (2016)

[9] B. Liu, Y.F. Zheng, Acta Biomater. 7, 1407 (2011)

[10] T. Kraus, F. Moszner, S. Fischerauer, M. Fiedler, E. Martinelli, J. Eichler, F. Witte, E. Willbold, M. Schinhammer, M. Meischel, P.J. Uggowitzer, J.F. Löffler, A. Weinberg, Acta Biomater. 10, 3346 (2014)

[11] M. Peuster, P. Wohlsein, M. Brügmann, M. Ehlerding, K. Seidler, C. Fink, H. Brauer, A. Fischer, G. Hausdorf, Heart 86, 563 (2001)

[12] M. Peuster, C. Hesse, T. Schloo, C. Fink, P. Beerbaum, C.V. Schnakenburg, Biomaterials 27, 4955 (2006)

[13] H. Hermawan, D. Dubé, D. Mantovani, Acta Biomater. 6, 1693 (2010)

[14] M. Schinhammer, A.C. Hänzi, J.F. Löffler, P.J. Uggowitzer, Acta Biomater. 6, 1705 (2010)

[15] H. Hermawan, D. Dubé, D. Mantovani, J. Biomed. Mater. Res. A 93A, 1 (2010)

[16] H. Hermawan, A. Purnama, D. Dubé, J. Couet, D. Mantovani, Acta Biomater. 6, 1852 (2010)

[17] E. Mouzou, C. Paternoster, R. Tolouei, A. Purnama, P. Chevallier, D. Dubé, F. Prima, D. Mantovani, Mater. Sci. Eng. C 61, 564 (2016)

[18] B. Liu, Y.F. Zheng, L.Q. Ruan, Mater. Lett. 65, 540 (2011)

[19] R.Y. Liu, R.G. He, L.Q. Xu, S.F. Guo, Acta Metall. Sin. (Engl. Lett.) 31, 584 (2018)

[20] W.M. Huang, Calphad 13(3), 243 (1989)

[21] R. Balcon, R. Beyar, S. Chierchia, I.D. Scheerder, P.G. Hugenholtz, F. Kiemeneij, B. Meier, J. Meyer, J.P. Monassier, Eur. Heart J. 18, 1536 (1997)

[22] M. Moravej, F. Prima, M. Fiset, D. Mantovani, Acta Biomater. 6, $1726(2010)$

[23] S. Gollapudi, Corros. Sci. 62, 90 (2012)

[24] K.D. Ralston, N. Birbilis, C.H.J. Davies, Scr. Mater. 63, 1201 (2010)

[25] G.R. Argade, S.K. Panigrahi, R.S. Mishra, Corros. Sci. 58, 145 (2012)

[26] D.A. Jones, Mater. Des. 43, 8 (1996)

[27] X.N. Gu, Y.F. Zheng, Y. Cheng, S.P. Zhong, T.F. Xi, Biomaterials 30, 484 (2009)

[28] R.J. Frey, Ref. Rev. 24, 48 (1999)

[29] M.J. Ellenhorn, S. Schonwald, G. Ordog, J. Wasserberger, S.S. Ellenhorn, J. Emerg. Med. 15, 582 (1997)

[30] J. Fischer, D. Pröfrock, N. Hort, R. Willumeit, F. Feyerabend, Mater. Sci. Eng. B 176, 830 (2011)

[31] D. Bian, W.R. Zhou, J.X. Deng, Y. Liu, W.T. Li, X. Chu, P. Xiu, H. Cai, Y.H. Kou, B.G. Jiang, Y.F. Zheng, Acta Biomater. 64, 421 (2017)

[32] J.I. Rosales-Leal, M.A. Rodríguez-Valverde, G. Mazzaglia, P.J. Ramón-Torregrosa, L. Díaz-Rodríguez, O. García-Martínez, M. Vallecillo-Capilla, C. Ruiz, M.A. Cabrerizo-Vílchez, Colloid Surf. A 365, 222 (2010)

[33] L. Ponsonnet, K. Reybier, N. Jaffrezic, V. Comte, C. Lagneau, M. Lissac, C. Martelet, Mater. Sci. Eng. C 23, 551 (2003)

[34] X.P. Bi, Z.W. You, J. Gao, X.Q. Fan, Y.D. Wang, Acta Biomater. 10, 2814 (2014)

[35] H. Imai, Y. Tanaka, N. Nomura, H. Doi, Y. Tsutsumi, T. Ono, T. Hanawa, J. Mech. Behav. Biomed. 66, 152 (2017) 